\title{
Faktor-Faktor yang Mempengaruhi Kecenderungan Fraud Akuntansi di Pemerintah Desa
}

\author{
Nisa' Uzlifat Nashruah ${ }^{1}$ \\ Provita Wijayanti ${ }^{2}$ \\ 1,2 Universitas Islam Sultan Agung Semarang (UNISSULA) \\ email: ${ }^{1}$ nnashruah@gmail.com \\ email:2 provita.w@unissula.ac.id
}

\begin{abstract}
This study aims to identify and analyze the effectiveness of internal control, ethical culture of the organization and individual morality on the occurrence of the accounting fraud tendency in the Government of Village / Sub District of Sayung. The population in this study is the village government in the District or Village of Sayung. The samples in this study used the Convenience Sampling Technique. The samples used in this study involved 40 respondents from 20 Sub District of Sayung. Data were collected through questionnaires and processed by means of multiple linear regression analysis test. The tests is by using SPSS for Windows version 16.0. The results of this study indicate that: (1) the variable of effectiveness of internal control has significant negative effect on the tendency of the accounting fraud in the Government of Village / Sub District of Sayung, (2) the variable of ethical culture of the organization has no significant effect on the tendency of the accounting fraud in Government of Village / Sub District of Sayung, (3) the variable of individual morality has significant negative effect on the tendency of the accounting fraud in the Government of Village / Sub District of Sayung.
\end{abstract}

Keywords: Internal Control, Ethical Culture of the organization, Individual Morality, Accounting Fraud Trends.

\section{PENDAHULUAN}

\section{Latar Belakang}

Kerugian pada dunia akuntansi salah satunya adalah fraud. Fenomena fraud tidak hanya terjadi di dunia tetapi juga terjadi di Indonesia. Fraud merupakan ancaman yang menarik bagi dunia ekonomi, mengingat berapa total jumlah uang yang hilang. Fraud pada laporan keuangan ini disebut fraud akuntansi. Fraud adalah suatu bentuk penipuan secara sengaja yang dilakukan oleh seorang maupun kelompok untuk mendapatkan keuntungan dan menimbulkan kerugian bagi pihak lain. Kecurangan akuntansi sangat terkait dengan korupsi. Tindakan-tindakan kecurangan akuntansi meliputi manipulasi, salah saji, dan penyelewengan yang di lakukan secara oleh seorang atau sekelompok dalam menyajikan laporan keuangan. Efektifnya sebuah pengendalian internal pada suatu entitas dapat memberikan kepercayaan bagi orang lain atas informasi dan laporan yang disajikan akan secara wajar (Delfi et al., 2014). Wijayanti dan Hanafi juga menyatakan bahwa pengendalian internal yang efektif dapat mempengaruhi kelancaran kegiatan operasional di bagian keuangan. Berdasarkan uraian tersebut dapat dikatakan bahwa makin baik dan efisien pengendalian intern pada organisasi maka akan makin sedikit kemungkinan fraud akuntansi. 
Rae dan Subramaniam (2008) dalam Artini et al. (2014) menyatakan seseorang akan cenderung untuk menjalankan peraturan-peraturan yang ditetapkan untuk menghindari perbuatan yang menyimpang atau melakukan kecurangan dilingkungan yang etis, sehingga dapat disebut sebagai lingkungan etis. Dengan adanya budaya etis organisasi sebaga calon pelanggar akan merasa malu karena rata-rata anggota dari organisasai tersebut memiliki integritas dan tanggung jawab untuk tidak melakukan kecurangan, sehingga calon pelanggar akan cenderung berpikir dua kali untuk melakukan fraud.

Moralitas individu akan memberikan kontribusi yang signifikan terhadap kecenderungan fraud akuntansi. Menurut Magnis (2001) moralitas merupakan sikap moral seseorang yang sebenarnya. Moralitas diartikan sebagai sikap hati dan tindakan lahiriah seseorang yang terungkap. Tingginya moralitas individu seorang karyawan akan mengurangi kecenderungan karyawan tersebut melakukan fraudakuntansi. Wijayanti dkk (2018) mengungkapkan bahwa fraud bisa berasal dari perasaan karena telah berjasa terhadap organisasi sehingga menganggap wajar jika mereka menyisipkan imbalan tersebut ke pos keuangan lain untuk bisa mendapatkan imbalan tersebut. Rasionalisasi pelaku fraud akuntansi bisa terjadi karena faktor ketamakan (greeds) dan tekanan kebutuhan (needs). Karyawan yang memiliki moralitas individu yang baik akan menyampingkan rasa ketamakannya untuk kepentingan sendiri, Prawira et al. (2014) menjelaskan seseorang yang bermoral tinggi akan lebih memintingkan kepentingan universal dari pada kepentingan individunya dan menghindarkan diri untuk berbuat suatu kecenderungan fraud.

Penelitian ini dilakukan pada Pemerintah Desa/Kecamatan Sayung dipilih karena sejak disahkannya UU No.6 Tahun 2014 tentang Dana Desa, Dana Desa mengakibatkan dana APBN sebesar Rp. 1 milyar yang bisa dimulai diambil secara bertahap pada tahun 2015. Pemerintah Desa sudah mendapatkan dana APBNDesa langsung dari pemerintah pusat yang digunakan untuk membangun desa sehingga setiap desa harus bertanggungjawab untuk melaporkan dana tersebut.

Penelitian ini mereplikasi dan memodifikasi dari penelitian Artini et al. (2014). Penelitian tersebut menggunakan efektifitas pengendalian internal dan budaya etis organisasi sebagai variabel bebas dan menggunakan kecenderungan kecurangan akuntansi sebagai variabel terikat. Penelitian ini menambahkan variabel moralitas individu sebagai modifikasi dari penelitian Artini et al. (2014). Penambahan variabel independen moralitas individu pada penelitian ini disebabkan karena moralitas individu dari karyawan sangan mempengaruhi kecenderungan fraud. Hal tersebut dapat dikatakan karena, jika seseorang memiliki moralitas yang tinggi dia cenderung memiliki integritas yang baik dan enggan melanggar peraturan walaupun pada saat itu ada kesempatan untuk melakukan kecurangan.

\section{Tinjauan Pustaka}

Teori keagenan dalam Ningsaptiti (2010) menjelaskan tentang fraud akuntansi. Teori agensi memiliki maksud untuk metelesaikan masalah yang sering terjadi dalam hubungan keagenan. Masalah pertama yang sering muncul dalam hubungan keagenan adalah perbedaan kepentingan antara agen dan prinsipal, masalah tersebut disebabkan karena adanya asimetri informasi (Kusumastuti dan Meiranto 2012). Asimetri informasi dapat diartikan dengan perbedaan informasi antara agen dan prinsipal. Pada teori agensi yang demikian 
dapat menimbulkan kecenderungan fraud yang tinggi jika tidak adanya pengawasan dan moral yang baik.

Kecenderungan fraud berdasarkan dari prespektif teori dapat disebabkan oleh peluang, tekanan dan rasionalisasi atau biasa disebut dengan fraud triangle (Hollow, 2014). Cabang pertama dari fraud triangle merupakan peluang. Peluang pada penelitian ini dapat diartikan dengan kemungkinan terjadinya kecurangan pada suatu entitas. Peluang terjadinya kecurangan pada suatu organisasi salah satunya dapat disebabkan oleh lemahnya sistem pengendalian pada entitas. Dapat dikatakan peluang apabila calon pelanggar kecurangan merasa bahwa keadaannya saat itu ia dapat melakukan pelanggara/kecurangan untuk tujuan tertentu tanpa takut akan tertangkap, sehingga pengendalian internal yang efektif dapat mencegah calon pelanggar merasa dia akan lolos jika ia melakukan pelanggaran pada entitas tersebut. Cabang yang kedua fraud triangle merupakan tekanan. Tekanan keadaan keuangan menjadi faktor penting bagi calon pelanggar untuk berpikir melakukan kecurangan. Masalah keuangan merupakan masalah pribadi bagi individu, mereka akan terlalu malu untuk berbagi masalahnya kepada orang lain. Moralitas individu yang baik akan mencegah pribadi melakukan kecurangan walaupun dengan tekanan seberat apapun. Hal tersebut dapat terjadi karena jika seorang indvidu tertanam moralitas yang baik dan memiliki nilai dan norma yang baik pula dia akan cenderung menghindari pelanggaran peraturan. Komponen ketiga dan terakhir dari fraud triangle adalah rasionalisasi. Cressey (1953) menemukan bahwa banyak pelanggar tidak pernah merasa bahwa mereka sebenarnya penjahat. Ini karena mereka merasa kesalahan itu tidak apa-apa. Banyak pelanggar yang diwawancarai Cressey (1953) merasa bahwa mereka dibenarkan. Alih-alih, tindakan itu merupakan bagian dari tanggung jawab umum yang mereka tidak sepenuhnya bertanggung jawab. Berdasarkan uraian tersebut, untuk membentuk individu yang memiliki moral yang baik dibutuhkan budaya etis organisasi. Suatu organisasi jika memiliki budaya etis yang baik maka akan menciptkan lingkungan kerja yang baik serta berbudi luhur. Lingkungan kerja yang berbudi luhur akan cenderung mendorong karyawan untuk tidal melanggar peraturan dan norma-norma yang telah ditetapkan.

\section{Kecenderungan Fraud Akuntansi Dipengaruhi Secara Negatif Oleh Efektifitas Pengendalian Internal}

Pengendalian intern disusun oleh suatu entitas untuk mengelola dan mengidentifikasi resiko . Menyusun pengendalian internal yang baik dan efektif telah menjadi isu yang sedang hangat karena tingginya kasus penipuan yang telah terjadi saat ini. Pencurian, penggelapan dan fraud dapat dicegah/dikurangi. Berdasarkan pendapat Davia dkk, (2000:119) dalam Delfi et al (2014) fraud akuntansi dapat dicegah dengan disusunnya pengendalian intern yang efektif.

Kecurangan dapat dilakukan pelanggar saat dirasa mempunyai kesempatan, serta kemungkinan terungkapnya kecurangan tersebut kecil. Menurut penelitian Murphy dan Dacin (2011) individu sering lebih percaya mampu menyembunyikan kesalahan mereka dan dapat menghindari hukuman. Melalui pengendalian internal yang baik dan efektif dapat mencegah calon pelanggar berpikir jika ia akan lolos jika melakukan kecurangan. Hasil penelitian Artini et al (2014) menjelaskan bahwa jika efektifitas pengendalian internal tinggi maka kecenderungan akuntansi akan rendah terjadi dan dapat menghasilkan tujuan yang baik.

$\mathrm{H}$ 1: Kecenderungan fraud akuntansi dipengaruhi secara negatif oleh efektifitas pengendalian internal 


\section{Kecenderungan Fraud Akuntansi Dipengaruhi Secara Negatif oleh Budaya Etis Organisasi}

Budaya etis organisasi merupakan nilai dan norma berbudi luhur yang mengarah pada perilaku semua anggota dari suatu organisasi atau entitas. Perilaku tidak etis dapat diartikan dengan menyimpangnya perilaku dari anggota organisasi untuk memperoleh keuntungan pribadinya atau pun klompok tertentu. Budaya etis organisasi yang kokoh dapat menurunkan kecenderungan fraud akuntansi, dengan membangun budaya etis organisasi perilaku seseorang dapat terpengaruhi dan budaya organisasi yang etis diharapkan dapat meningkatkan keberhasilan kinerja organisasi (Wijayanti dan Hanafi, 2018). Kecenderungan kecurangan dapat diminimalisasi dan dicegah dengan bidaya etiis organisasi. Baiknya budaya etis organisasii maka moral individu pada organisasi tersebut baik. Rae dan Subramaniam (2008) dalam Pramudita (2013) organisasi yang mempunyai perilaku yang etis dan lingkungan yang baik maka individu akan lebih cenderung melakukan sesuatu hal yang baik sesuai peraturan dan menghindari tindak kecurangan. Lingkungan yang baik ini dapat dinilai dari budaya etis organisasi. Menurut penelitia Artini et al (2014) dan Pristiyanti (2013) Jika budaya etis organisasi itu tinggi maka kecenderungan kecurangan akuntansi akan rendah terjadi sehingga dapat menciptakan hasil yang baik.

H2: $\quad$ Kecenderungan fraud akuntansi dipengaruhi secara negatif oleh budaya etis organisasi

\section{Kecenderungan Fraud Akuntansi Dipengaruhi Secara Negatif Oleh Moralitas Individu}

Berbagai bukti empiris menyatakn bahwa fraud muncul karena dipengarihi oleh 2 (dua) faktor yaitu internali dan eksternal. Salah satu dari fakto internal yang dapat menyebabkan munculnya fraud ialah perilaku individu. Perilaku individu dapat menjadi salah satu faktor munculnya fraud (Ramamoorti, 2008). Hal tersebut disebabkan, jika individu tersebut memiliki perangai dan moral yang buruk maka meskipun dengan efektifnya pengendalian intern suatu entitas dia akan tetap mencari celah. Puspasari (2012) menjelaskan bahwa etisnya perilaku seseorang diipengaruhi oleh penalarran moralnya. Seseorang dengan level penalarran morall yang rendah cenderung berperilaku yang menunjukkan perilaku mengintungkan dirinya sendiri. Sesorang dengan moralyang akan berperilaku yang baik dan tidak hanya dilakukan dengan keuntungan diri sendiri tetapi juga umum. Pada penelitian Prawira et al (2014) menjelaskan tingginya moralitas individu yang dimiliki seseorang maka individui tersebuti akan semakin memperhatikani kepentingani universal dari pada kepentingan individunya dan menghindarkan diri untuk berbuat suatu kecenderungan fraud akuntansi.

H3: $\quad$ Kecenderungan fraud akuntansi dipengaruhi secara negatif oleh moralitas individu.

\section{METODOLOGI PENELITIAN}

\section{Definisi Operasional Variabel}

\section{Pemilihan Sampel dan Data Pengumpulan}

Populasi pada penelitian ini adalah pemerintah/perangkat desa yang bekerja di seluruh Kelurahan Kecamatan Sayung dan menggunakan metode purposive sampling sebagai pengambilan sampelnya dengan melakukan survei penyebaran kuesioner.. 
Dengan kriteria :

1. Kepala Desa Kelurahan Kecamatan Sayung

2. Perangkat Desa Kelurahan Kecamatan Sayung yang berada pada bagian keuangan.

\section{Metode Analisis Data}

\section{Analisis Regresi Linier Berganda}

Hipotesis pada penelitian ini akan diuji menggunakan SPSS V.16 dengan analisis regresi linier berganda. Model persamaan regresi pada penelitianini adalah:

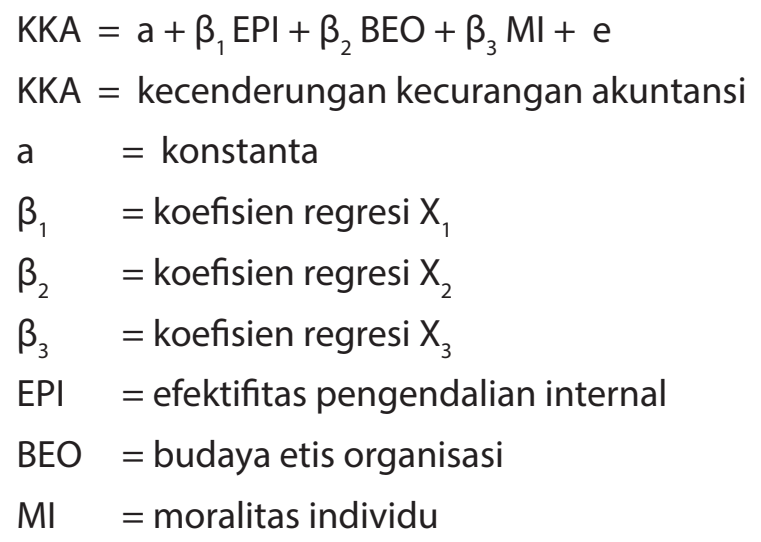

\section{HASIL DAN PEMBAHASAN}

\section{Hasil Uji Normalitas}

Diperoleh angka signifikan 0,774 > 0,05, jadi penelitianiini memiliiki distribusii normal. Berdasarkan tabel 4.7 diatas variabel independen nilai tolerance lebih besari dari 0,1 dan VIF tidak lebih dari 10. Jadi model regresi tidak terjadi multikolinearitas.

\section{Hasil Uji Analisi Regresi Linier Berganda}

Berdasarkan tabel 4.8 dapat dijelaskan bahwa:

1. Hasil uji hipotesis pertama Efektifitas Pengendalian Internal (X1)

Hasil pengujian untuk variabel efektifitas pengendalian internal (X1) menunjukkan bahwa nilai signifikansi 0,014 kurang dari 0,05. Angka tersebut dapat sitarik kesimpulan bahwa kecenderungan fraud akuntansi dapat dipengaruhi secara negatif oleh efektifitas pengendalian internal, dan menyatakan Ha diterimai dan Ho ditolak.

2. Hasil uji hipotesis kedua Budaya Etis Organisasi (X2)

Hasil pengujian untuk variabel budaya etis organisasi (X2) mengahasilkan siignifikansi 0,495 >0,05. Pada hasili tersebut dapati dikatakan bahwa kecenderungan fraud akuntansi tidak dapat dipengaruhi secara negatif oleh budaya etis organisasi. Angka tersebut menyatakan bahwa Ha ditolak serta Ho diterima.

3. Hasil uji hipotesis ketiga Moralitas Individu (X3)

Hasil pengujian untuk variabel moralitas individu (X3) menunjukkan bahwa nilai signifikansi 0,038< 
0,05. Hal tersebut menjelaskan bahwa kecenderungam fraud akuntansi dipengaruhi secara negatif oleh moralitas individu dan menyatakan Ha diterima dan Ho ditolak.

\section{Hasil Uji Koefisien Determinasi $\left(\mathbf{R}^{2}\right)$}

Berdasarkan tabel 4.9 nilai Adjusted $R$ Squarei yang didapati pada penelitiani ini sebesar 0,466, artinya 46,6\% kecenderungan fraud akuntansi bisa diterangkan oleh variabel independen, dan sisanya 53,4\% kecenderungan fraud akuntansi diterangkan oleh variabel-variabel lain.

Berdasarkan tabel 4.10 diatas menunjukan hasil bahwa $\mathrm{F}$ hitung $=12,356$ lebih besar dari $\mathrm{F}$ tabel $=2,87$ yang berarti Ha diterima dan Ho ditolak..

\section{PEMBAHASAN}

\section{Pengaruh Efektifitas Pengendalian Internal Terhadap Kecenderungan Fraud Akuntansi}

Penelitian ini menunjukkan bahwa kecenderungan fraud akuntansi dapat dipengaruhi secara negatif terhadap efektifitas pengendalian internal. Rendahnya fraud akuntansi di Pemerintah desa/kelurahan di Kecamatan Sayung Kabupaten Demak salah satunya dapat disebabkan efektifnya pengendalian intern entitas tersebut. Semakin tinggi efektifitas pengendalian internal yang dilihat dari penerapan wewenang dan tanggung jawab yang semakin baik maka kecenderungan fraud akuntansi yang akan terjadi semakin rendah, sehingga dapat disimpulkan dari penelitian ini bahwa hipotesis pertama diterima. Pengendalian internal yang efektif akan dapat memajukan organisasinya, seperti pada Kelurahan Sayung. Pembagian wewenang dan tanggung jawab yang baik, melakukan otorisasi dari pihak yang berwenang, menyertakan bukti pendukung transaksi, pemeriksaan fisik atas kekayaan yang baik, pencataan yang baik pada setiap kegiatan operasioanal dan pemantauan dengan evaluasi atas aktivitas operasional akan dapat menurunkan tingkat kecenderungan fraud akuntansi.

\section{Pengaruh Budaya Etis Organisasi Terhadap Kecenderungan Fraud Akuntansi.}

Penelitian ini menjelaskan bahwa kecenderungan fraud akuntansi tidak dapat dipengaruhi secara negatif oleh budaya etis organisasi. Uraian tersebut berarti pada Pemerintah Desa/Kelurahan Kecamatan Sayung kecenderungan fraud tidak dipengaruhi oleh budaya etis organisasi. Hal tersebut disebabkan pada dasarnya ada 2 faktor yang mempengaruhi perilaku seseorang yaitu faktorr eksterrnal dan interrnal. Faktir eksternal yang diciptakan dari orang-orang yang bekerja pada Kelurahan Kecamatan Sayung belum dapat menjadi indikator tinggi/rendahnya kecenderungan fraud akuntansi pada entitas tersebut. Selain itu faktor internal yang kuat dapat mempengaruhi perilaku dan cara bertindak. Apabila budaya organisasi yang ditanamkan pada Kelurahan Sayung itu baik, sedangkan moral dalam diri sendiri kurang baik itu dapat menyebabkan perilaku yang menyimpang dan tidak sesuai dengan prosedur yang ditetapkan.

\section{Pengaruh Moralitas Individu Terhadap Kecenderungan Fraud Akuntansi}

Hasil penelitian ini menjelaskan bahwa kecenderungan fraud akuntansi dapat dipengaruhi secara negatif 
oleh moralitas individu, sehingga dapat dikatakan semakin baik moral pada setiap sesorang maka akan dapat menurunkan kecenderungan fraud akuntansi pada Pemerintah Desa/Kelurahan Kecamatan Sayung. Semakin baik moralitas individu yang dimiliki dapat dilihat dari tingkat kejujurannya yang baik maka kecenderungan fraud akuntansi yang akan terjadi akan semakin menurun., sehingga dapat disimpulkan dari penelitian ini bahwa hipotesis ketiga diterima. Ketika moral pada setiap individu kuat dan memiliki integritas, maka individu tersebut juga tidak akan menyimpang dari peraturan yang berlaku dan enggan melakukan fraud meskipun ada kesempatan ia dapat melakukannya. Dapat dikatakan memiliki moralitas individu yang tinggi apabila individu mengertu hak, kewajiban, tangging jawabnya serta kepentingan universal dani bukan hanya mencarri keuntungan untuk dirinya sendiri.

\section{KESIMPULAN DAN SARAN}

\section{Kesimpulan}

Simpulan dari penelitian ini adalah kecenderungan fraud akuntansi tidak dipengaruhi secara negatif oleh efektifitasi pengendalian internal dan moralitas, sedangkan budaya etis organisasi tidak berpengaruh terhadap kecendurungan fraud akuntansi.

\section{Saran}

Adapun saran untuk penelitian dimasa mendatang yaitu:

Memperluas daerah penelitian dan memperbanyak jumlah responden.

Diharapkan pada pihak Pemerintah Desa/Kelurahan Kecamatan Sayung untuk semakin meningkatkan efektifitas pengendalian internal nya.

Diharapkan pada pihak Pemerintah Desa/Kelurahan Kecamatan Sayung untuk semakin meningkatkan budaya etis organisasinya melalui pelatihan-pelatihan etis yang dilakukan secara lebih baik.

Diharapkan pada pihak Pemerintah Desa/Kelurahan Kecamatan Sayung untuk semakin meningkatkan moralitas individu pada dirinya melalui tingkat kejujuran yang semakin tinggi. 


\section{DAFTAR PUSTAKA}

Artini, Ari Eka. 2014. Pengaruh Budaya Etis Organisasi dan Efektivitas Pengendalian Internal terhadap Kecenderungan Kecurangan Akuntansi Pada Satuan Kerja Perangkat Daerah (SKPD) Kabupaten Jembrana. Skripsi. Fakultas Ekonomi dan Bisnis: Universitas Pendidikan Ganesha.

Delfi, Tiara, Rita A., Al Azhar A., Desmiyawati. 2014. Pengaruh Efektifitas Pengendalian Internal dan Kesesuaian Kompensasi terhadap Kecenderungan Akuntansi: Survey pada Perusahaan BUMN Cabang Pekanbaru. Simposium Nasional Akuntansi (SNA) 17 Mataram. Lombok, 24-27 September 2014.

Ghozali,Imam, 2013. Aplikasi Analisis Multivariat dengan Program IBM SPSS 21.Edisi7, Penerbit Universitas Diponegoro, Semarang.

Gusmaiini, Welli; Fauziati, Popi dan Yustia Resti, 2014. Pengaruh Sistem Pengendalian Internal, Sistem Kompensasi dan Asimetri Informasi terhadap Kecenderungan Kecurangan Akuntansi. Jurnal FE Universitas Bung Hatta.

Hollow, M. (2014).Money, Morals and Motives: An Exploratory Study into Why Bank Managers and Employees Commit Fraud at Work. Journal of Financial Crime, 21(2), 174(2)

Magnis-Suseno, Franz, 1988. Etika Politik: Prinsip-prinsip Moral Dasar Kenegaraan Modern, Gramedia Pustaka Utama, Jakarta.

Najaningrum, Anik Fatun, 2013. Faktor-faktor yang Mempengaruhi Fraud: Persepsi Pegawai Dinas Provinsi DIY. Accounting Analysis Journal Vol. 2 No. 3 Tahun 2013.ISSN. 2252-6765.

Pramudita, Aditya. 2013. Faktor -Faktor Yang Mempengaruhi Terjadinya Fraud Di Sektor Pemerintahan (Persepsi Pegawai Pada Dinas Se-Kota Salatiga).Skripsi Universitas Negeri Semarang: Semarang.

Prawira, I Made D., Nyoman Trisna H., dan Nyoman Ari S.D. 2014. " Pengaruh Moralitas Individu, Asimetri informasi dan Efektivitas Pengendalian Internal Terhadap Kecenderungan Kecurangan (Fraud) akuntansi". E-Journal S1 Ak. Universitas Pendidikan Ganesha.

Pristiyani, Ari dkk. 2013. "Problema Sosial Projo dan Brojo Karya Arswendo Atmowiloto dan Implikasinya dalam Pengajaran". Jurnal Kata (Bahasa, Sastra, dan Pembelajarannya). Universitas Lampung.

Puspasari, Novita dan Eko Suwardi. 2012. Pengaruh Moralitas Individu dan Pengendalian Internal Terhadap Kecenderungan Kecurangan Akuntansi: Studi Eksperimen Pada Konteks Pemerintahan Daerah. Skripsi. Universitas Gajah Mada.

Rae ,Kristy. and Subramaniam (2008), " Quality of internal control procedures: Antecedents and moderating effect on organisational justice and employee fraud", Managerial Auditing Journal, Vol. 23 No. 2, pp.104124.

Wijayanti, Provita dan Rustam Hanafi. 2018. Pencegahan Fraud Akuntansi Di Pemerintah Desa. Jurnal Multi Paradigma Vol. 9 No.2.

Wilopo. 2006. AnalisisFaktor-faktor yang Berpengaruh terhadap Kecenderungan Kecurangan Akuntansi: Studi pada Perusahaan Publik dan Badan Usaha Milik Negara di Indonesia. Makalah.SNA 9 Padang. 


\section{LAMPIRAN}

Tabel 3. 1 Definisi Operasional Variabel

\begin{tabular}{|c|c|c|}
\hline Variabel & Indikator & Pengukuran \\
\hline Independen : & 1. Penerapan wewenang & Skala Likert 1-5 \\
\hline \multirow[t]{5}{*}{ Efektifitas Pengendalian Internal } & 2. Pencatatan transaksi & \\
\hline & 3. Pengendalian fisik & \\
\hline & 4. Sistem akuntansi & \\
\hline & 5. Pemantauan & \\
\hline & 6. Evaluasi. & \\
\hline Independen : & 1. Model peran yang visible & Skala Likert 1-5 \\
\hline \multirow[t]{4}{*}{ Budaya Etis Organisasi } & 2. Komunikasi harapan-harapan etis & \\
\hline & 3. Pelatihan etis & \\
\hline & 4. Hukuman bagi tindakan tidak etis & \\
\hline & 5. Mekanisme perlindungan etika & \\
\hline Independen : & 1. Kejujuran pembuatan laporan keuangan & Skala Likert 1-5 \\
\hline \multirow[t]{3}{*}{ Moralitas Individu } & 2. Penolakan barang/uang suap & \\
\hline & $\begin{array}{l}\text { 3. Tanggung jawab pekerjaan, aturan } \\
\text { hukum pembuatan laporan keuangan }\end{array}$ & \\
\hline & $\begin{array}{l}\text { 4. Peduli dengan eksternal tidak hanya } \\
\text { internal }\end{array}$ & \\
\hline Dependen : & 1. Manipulasi pencatatan akuntansi & Skala Likert 1-5 \\
\hline \multirow[t]{6}{*}{ Kecenderungan Fraud Akuntansi } & $\begin{array}{l}\text { 2. Penyajian yang salah pada laporan } \\
\text { keuangan }\end{array}$ & \\
\hline & $\begin{array}{l}\text { 3. Salah menerapkan prinsip akuntansi } \\
\text { secara sengaja }\end{array}$ & \\
\hline & $\begin{array}{l}\text { 4. Penyajian laporan keuangan yang salah } \\
\text { akibat pencurian }\end{array}$ & \\
\hline & 5. Penyajian laporan keuangan yang salah & \\
\hline & akibat perlakuan yang tidak semestinya & \\
\hline & terhadap aktiva & \\
\hline
\end{tabular}

Sumber : Wilopo (2006)

Tabel 4.1 Responden Kuesioner

\begin{tabular}{lcc}
\hline \multicolumn{1}{c}{ Keterangan } & $\begin{array}{c}\text { Jumlah } \\
\text { Kuesioner }\end{array}$ & Prosentanse \\
\hline Kuesioner disebarkan & 40 & $100 \%$ \\
Kuesioner tidak kembali & 0 & $0 \%$ \\
Kuesioner kembali & 40 & $100 \%$ \\
Kuesioner tidak dapat diolah & 0 & $0 \%$ \\
Kuesioner dapat diolah & 40 & $100 \%$ \\
\hline
\end{tabular}

Sumber: data primer yang diolah tahun 2017

Faktor-Faktor yang Mempengaruhi Kecenderungan Fraud Akuntansi di Pemerintah Desa 
Tabel 4.2 Data Sampel Penelitian

\begin{tabular}{|c|c|c|}
\hline $\begin{array}{c}\text { Keterangan } \\
\text { Jumlah Sampel } \\
\text { Umur }\end{array}$ & $\begin{array}{c}\text { Frekuensi } \\
40\end{array}$ & $\begin{array}{c}\text { Persentase } \\
100 \%\end{array}$ \\
\hline $25-35$ th & 12 & $30 \%$ \\
\hline $36-46$ th & 13 & $32.5 \%$ \\
\hline $47-57$ th & 11 & $27.5 \%$ \\
\hline$>57$ th & 4 & $10 \%$ \\
\hline \multicolumn{3}{|l|}{ Jenis Kelamin } \\
\hline Laki-laki & 38 & $95 \%$ \\
\hline Perempuan & 2 & $5 \%$ \\
\hline \multicolumn{3}{|l|}{ Masa Kerja } \\
\hline$<2$ th & 20 & $50 \%$ \\
\hline $3-9$ th & 8 & $20 \%$ \\
\hline $10-15$ th & 1 & $2.5 \%$ \\
\hline$>15$ th & 11 & $27.5 \%$ \\
\hline \multicolumn{3}{|l|}{ Pendidikan } \\
\hline SD & 1 & $2.5 \%$ \\
\hline SMP & 4 & $10 \%$ \\
\hline SMA & 25 & $62.5 \%$ \\
\hline D3 & 1 & $2.5 \%$ \\
\hline S1 & 8 & $20 \%$ \\
\hline S2 & 1 & $2.5 \%$ \\
\hline
\end{tabular}

Tabel 4.3 Deskripsi Responden

\begin{tabular}{lcccccc}
\hline & N & Min & Max & Sum & Mean & Std. Dev \\
\hline $\begin{array}{l}\text { Efektifitas Pengendalian } \\
\text { Internal }\end{array}$ & 40 & 19 & 25 & 887 & 22.18 & 1.933 \\
Budaya Etis Orgaisasi & 40 & 15 & 25 & 833 & 20.82 & 2.510 \\
Moralitas Individu & 40 & 15 & 25 & 865 & 21.62 & 2.835 \\
$\begin{array}{l}\text { Kecenderungan } \\
\text { Kecurangan Akuntansi }\end{array}$ & 40 & 5 & 16 & 332 & 8.30 & 2.893 \\
Valid N (listwise) & 40 & & & & & \\
\hline
\end{tabular}

Sumber: Data primer yang diolah, 2017 
Tabel 4.4 Hasil Uji Statistik Deskriptif

\begin{tabular}{ccccc}
\hline Variabel & Pernyataan & r hitung & r tabel & Keterangan \\
\hline Efektifitas & EPI 1 & 0,616 & 0,312 & Valid \\
Pengendalian & EPI 2 & 0,747 & 0,312 & Valid \\
Internal & EPI 3 & 0,699 & 0,312 & Valid \\
& EPI 4 & 0,785 & 0,312 & Valid \\
Budaya Etis Organisasi & EPI 5 & 0,625 & 0,312 & Valid \\
& BEO 1 & 0,608 & 0,312 & Valid \\
& BEO 2 & 0,637 & 0,312 & Valid \\
& BEO 3 & 0,605 & 0,312 & Valid \\
Moralitas Individu & BEO 4 & 0,710 & 0,312 & Valid \\
& BEO 5 & 0,659 & 0,312 & Valid \\
& MI 1 & 0,829 & 0,312 & Valid \\
& MI 2 & 0,783 & 0,312 & Valid \\
& MI 3 & 0,867 & 0,312 & Valid \\
& MI 4 & 0,922 & 0,312 & Valid \\
& MI 5 & 0,855 & 0,312 & Valid \\
& KKA 1 & 0,586 & 0,312 & Valid \\
& & & & \\
& KKA 2 & 0,754 & 0,312 & Valid \\
& KKA 3 & 0,644 & 0,312 & Valid \\
& KKA 4 & 0,701 & 0,312 & Valid \\
& KKA 5 & 0,834 & 0,312 & Valid \\
\hline
\end{tabular}

Sumber: Data primer yang diolah, 2017

Tabel 4.5 Hasil Uji Validitas

$\begin{array}{lcc}\begin{array}{l}\text { Valid karena } r_{\text {hitung }} \text { lebih besar dari } r_{\text {tabel }}(0,312) . \\ \text { Cronbach's Alpha }\end{array} & \text { Keterangan } \\ \text { Variabel } & 0,731 & \text { Reliabel } \\ \text { lian Internal } & 0,625 & \text { Reliabel } \\ \text { Casi } & 0,901 & \text { Reliabel } \\ & 0,744 & \text { Reliabel }\end{array}$

Sumber: Data primer yang diolah, 2017 
Tabel 4.6 Reliable karena nilai cronbach alpha > 0,6.

\begin{tabular}{llr}
\hline & & Unstandardized Residual \\
\hline $\mathrm{N}$ & & 40 \\
Normal Parameters & a & .0000000 \\
& Std. Deviation & 1.44803429 \\
Most Extreme Differences & Absolute & .105 \\
& Positive & .105 \\
& Negative & -.080 \\
Kolmogorov-Smirnov Z & & .661 \\
Asymp. Sig. (2-tailed) & & .774 \\
\hline
\end{tabular}

Sumber: Data primer yang diolah, 2017.

Tabel 4.7 Hasil Uji Multikolonieritas

\begin{tabular}{lcr}
\hline \multirow{2}{*}{ Model } & \multicolumn{2}{c}{ Collinearity Statistics } \\
& Tolerance & VIF \\
\hline Efektifitas Pengendalian Internal & 0,468 & 2,138 \\
Budaya Etis Organisasi & 0,714 & 1,401 \\
Moralitas Individu & 0,450 & 2,222 \\
\hline
\end{tabular}

\section{Tabel 4.8}

\begin{tabular}{|c|c|c|c|c|c|c|}
\hline \multirow{2}{*}{\multicolumn{2}{|c|}{ Model B Std. Error Beta }} & \multirow{2}{*}{\multicolumn{2}{|c|}{ Unstandardized Coefficients }} & \multicolumn{3}{|l|}{ Standardized } \\
\hline & & & & \multirow[t]{2}{*}{ Coefficients } & $\mathrm{T}$ & \multirow{2}{*}{$\begin{array}{l}\text { Sig. } \\
\qquad .000\end{array}$} \\
\hline \multirow{4}{*}{1} & (Constant) & 24.577 & 3.346 & & 7.346 & \\
\hline & Efektifitas Pengendalian Internal & -.511 & .198 & -.442 & -2.585 & .014 \\
\hline & Budaya Etis Organisasi & .100 & .145 & .095 & .690 & .495 \\
\hline & Moralitas Individu & -.345 & .160 & -.376 & -2.155 & .038 \\
\hline
\end{tabular}

Tabel 4.9

\begin{tabular}{ccccc}
\hline Model & $\mathrm{R}$ & R Square & Adjusted R Square & $\begin{array}{c}\text { Std. Error of the } \\
\text { Estimate }\end{array}$ \\
\hline 1 & $.712^{\mathrm{a}}$ & .507 & .466 & 1.507 \\
\hline
\end{tabular}

Sumber : Data primer yang diolah, 2017 
Tabel 4.10 Hasil Uji F

\begin{tabular}{|c|c|c|c|c|c|c|}
\hline \multicolumn{7}{|c|}{ ANOVA $^{b}$} \\
\hline \multirow{2}{*}{\multicolumn{2}{|c|}{ Model }} & & Df & Mean & $\mathrm{F}$ & Siq. \\
\hline & & Squares & & Square & & \\
\hline \multirow[b]{2}{*}{1} & Regression & 84.200 & 3 & 28.067 & 12.356 & $.000^{\mathrm{a}}$ \\
\hline & $\begin{array}{l}\text { Residual } \\
\text { Total }\end{array}$ & $\begin{array}{r}81.775 \\
165.975\end{array}$ & $\begin{array}{l}36 \\
39\end{array}$ & 2.272 & & \\
\hline
\end{tabular}

\section{Gambar 2 Hasil Uji Heteroskedastisitas}

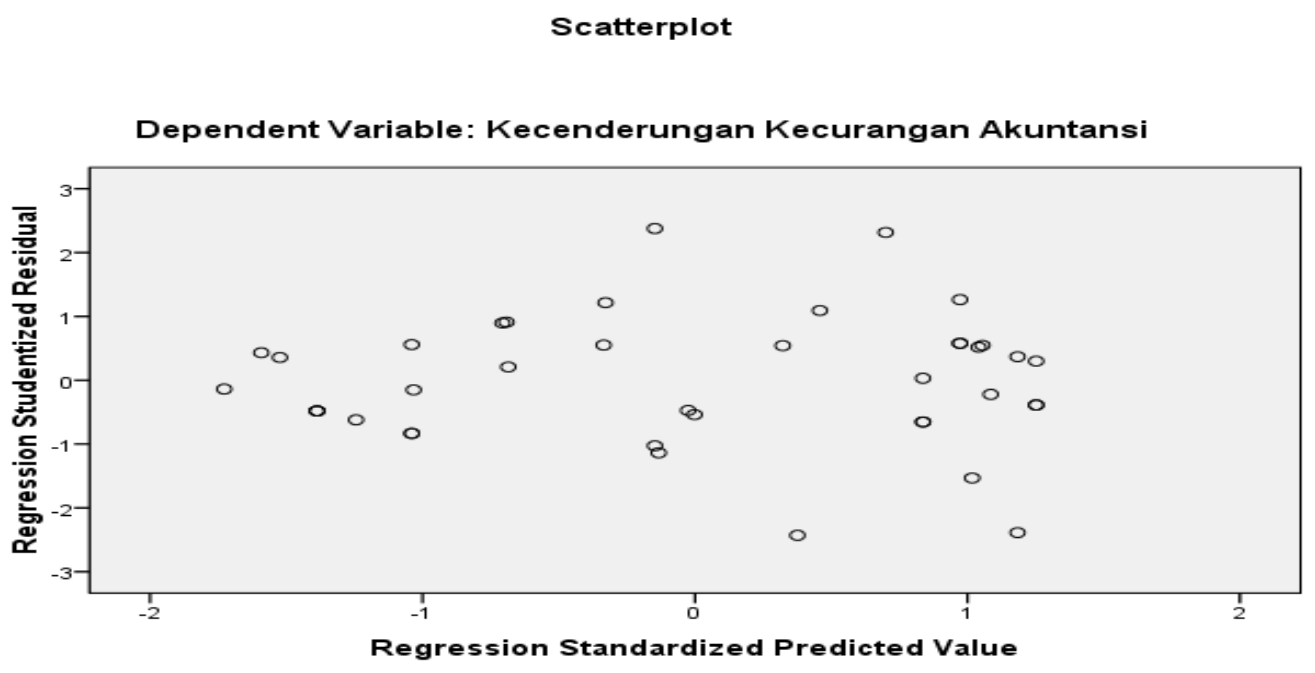

Sumber: Data primer yang diolah, 2017. 